\title{
Validity of the PHQ-9 and PHQ-2 to screen for depression in nationwide primary care population in Latvia
}

\author{
Elmars Rancans ${ }^{1}$, Marcis Trapencieris ${ }^{2}$, Rolands Ivanovs ${ }^{1}$ and Jelena Vrublevska ${ }^{1 *}$ (i)
}

\begin{abstract}
Background: Depression is highly underdiagnosed in primary care settings in Latvia. Screening for depression in primary care is potentially an efficient way to find undetected case $s$ and improve diagnostics. We aimed to validate both a nine-item and two-item Patient Health Questionnaire (PHQ-9 and PHQ-2) in the Latvian and Russian languages in primary care settings using a representative sample in Latvia.

Materials and methods: The study was carried out within the framework of the National Research Program BIOMEDICINE to assess the prevalence of mental disorders at 24 primary care facilities. During a 1-week period, all consecutive adult patients were invited to complete the PHQ-9 and PHQ-2. Criterion validity was assessed against the Mini International Neuropsychiatric Interview (MINI).

Results: There were 1467 patients who completed the PHQ-9 and the MINI. Overall, the PHQ-9 items showed good internal reliability (Cronbach's alpha 0.81 for Latvian version and 0.79 for Russian version of the PHQ-9). A cut-off score of 8 or greater was established for the PHQ-9 (sensitivity 0.75 and 0.79 , specificity 0.84 and 0.80 for Latvian and Russian languages, respectively). For the PHQ-2, a score of 2 or higher (sensitivity 0.79 and 0.79 , specificity 0.65 and 0.67 for Latvian and Russian languages) detected more cases of depression than a score of 3 or higher.
\end{abstract}

Conclusions: We suggest GPs ask patients to respond to the first 2 questions of the PHQ-9. If their score is positive, the patients should then complete the PHQ-9.

Keywords: Depression, Primary care, General practitioners, Validation

\section{Background}

Depression is a common psychiatric condition that has widespread consequences both at the individual and societal level. It is among the leading non-fatal diseases globally [1]. Long term consequences of depression include reduced quality of life, risk of suicide, increased rates of hospital admission, increased risk for chronical medical conditions and stigmatization [2-5].

The WHO study on psychological problems in general health care across 14 countries found that $14 \%$ of individuals suffered from major depression [6]. Despite the

\footnotetext{
*Correspondence: vrublevskaja@inbox.Iv

1 Department of Psychiatry and Narcology, Riga Stradins University, Tvaika Street 2, Riga 1005, Latvia

Full list of author information is available at the end of the article
}

fact that most care for depression is delivered by general practitioners, under-recognition of depression has been extensively described [7]. Depression is often underdetected in primary care: approximately $50 \%$ of GPs correctly identify depression cases, and even fewer, 34\%, record it in their notes [8].

Despite rich data from studies of depression in primary care in Western Europe $[9,10]$, there still is a need for studies from Eastern Europe [11]. The best available data suggest that under-diagnosis of depression is particularly salient for Latvia, where the 12-month prevalence of depression has been estimated at $7.8 \%$, but according to the data from the Latvian National Health Service, only 4423 unique patients have been diagnosed with a mood disorder by general practitioners (GPs) $[12,13]$.

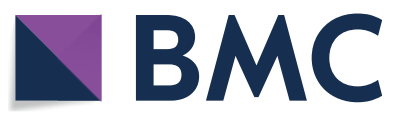

(c) The Author(s) 2018. This article is distributed under the terms of the Creative Commons Attribution 4.0 International License (http://creativecommons.org/licenses/by/4.0/), which permits unrestricted use, distribution, and reproduction in any medium, provided you give appropriate credit to the original author(s) and the source, provide a link to the Creative Commons license, and indicate if changes were made. The Creative Commons Public Domain Dedication waiver (http://creativecommons.org/ publicdomain/zero/1.0/) applies to the data made available in this article, unless otherwise stated. 
Because of large estimates of underdiagnosed and undertreated depression in primary care, improved screening could reduce the burden of depression. Routine primary care screening can facilitate improvement of the diagnosis rates of adult depression and has been recommended by the US Preventive Services Task Force [14, 15]. However, it is notable that some national guidelines doubt the effectiveness of screening for depression [16].

It is essential that depression screening tools are reliable and valid to ensure that the results they generate are clinically correct [17]. There are numerous studies assessing the reliability and validity of depression screening tools, but there is currently no consensus on one particular screening tool to be used for depression screening across primary healthcare settings [18]. Moreover, to be acceptable in practice, it is essential that instruments are easy and quick to use [19].

The Patient Health Questionnaire-9 (PHQ-9) was developed as a depression screener for depression in primary care. The PHQ-9 is a self-rating instrument for depression developed in the late 1990s from the Primary Care Evaluation of Mental Disorders (PRIME-MD) [20] and based on the Diagnostic and Statistical Manual of Mental Disorders, Fourth Edition (DSM-IV) criteria for MDD [21]. This tool consisting of 9 items is known for its ease of completion for the patient, ease of scoring and interpretation, and public availability. It is used among racially and ethnically diverse populations. Respondents rate the scale items from 0 to 3 according to the frequency of their experience over the previous 2-week period (not at all, several days, more than half the days, or nearly every day). A cut-off score of $\geq 10$ has been recommended for detecting cases of major depressive disorder (MDE) [21, 22]. Over 100 studies have examined the PHQ-9 in primary care [22]. Moreover, the PHQ-9 has been validated in medical populations [23-25], general populations [26-29] and psychiatric samples [30-34].

Of recent interest has been the use of fewer screening questions from the PHQ-9 $[35,36]$. The PHQ-2 was developed for depression screening, with some evidence for a role in diagnosing depression [35, 37, 38]. These 2 questions, collectively known as the PHQ-2, ask about the frequency of the symptoms of depressed mood and anhedonia, scoring each as 0 (not at all) to 3 (nearly every day). The validation study of the PHQ-2 by Kroenke et al. included a sample of 580 primary care patients [35].

A valid depression screener in Latvian and Russian is important for Latvia because $61.8 \%$ of the population is Latvian, with the remainder being people from Russian language-speaking nations (Russia, Belarus, and Ukraine) $[39,40]$.

The aim of our study was to validate the PHQ-9 and PHQ-2 in Latvian and Russian languages using the Mini
International Neuropsychiatric Interview (MINI) as the reference standard in a representative primary care sample.

\section{Materials and methods}

The current study was carried out in 2015 within the framework of the National Research Program, BIOMEDICINE 2014-2017, a cross-sectional study to assess the prevalence of mental disorders in primary care settings in Latvia. The study recruited patients from 24 primary care facilities all over the country that covered all regions of Latvia. The survey was conducted in the two most commonly spoken languages in Latvia (Latvian and Russian). The programme was financed by the Latvian Ministry of Education and Science. The main aim of this programme is to develop new prevention, treatment, and diagnostic methods and practices, as well as biomedical technologies to improve public health in Latvia. The programme has existed since 2007 and comprises certain areas: cardiovascular and metabolic diseases, oncological diseases, and childhood and infectious diseases. Mental health was included in the programme for the first time.

During a 1-week period in each GP's facility, all consecutive patients aged 18 years or older visiting a primary care physician with any health concerns were invited to participate in the study. Those who visited their GP for any administrative reasons were not included in the sample. No further restrictions on patient selection were implemented.

All consecutive patients were invited to complete the paper-and-pencil form of the PHQ-9 in the preferred language (Latvian or Russian) before seeing the GP, followed by interview with a structured socio-demographic questionnaire. All uncertainties and questions raised were explained by a psychiatrist. Both versions of the PHQ-9 in Latvia have been previously adapted and used in a nationwide general population study [41]. However, at that time, no cut-off score for Latvia was established, and a cut-off score $\geq 10$ has been applied as recommended by Kroenke et al. [21]. In 2014, within the pilot project of the National Research Programme, BIOMEDICINE, that was conducted at 6 primary care facilities, the cutoff score of the PHQ-9 of $\geq 10$ for both languages was established [42]. However, that study included validation of the PHQ-9 and not the PHQ-2 and had considerable limitations such as a small sample size that was not representative of the primary care population nationwide.

No more than 2 weeks after completing the PHQ-9, four psychiatrists who were blind to the PHQ-9 scores interviewed the respondents over the phone with the Mini International Neuropsychiatric Interview (MINI), Version 6.0.0. The MINI is a structured diagnostic interview that was validated by convergence with the 
Structured Clinical Interview for the DSM-III-R Patient Version (SCID-P) and the Composite International Diagnostic Interview (CIDI) and by expert professional opinion [43]. The good psychometric characteristics of the MINI, its ability to be administered rapidly, and its acceptability to patients made it a good choice for research purposes [44]. The MINI has been translated and adapted for both Latvian and Russian languages by the authorship holders and previously has been used in population-based study [13]. The MINI was used as the standard to determine the presence of major depressive episodes and was conducted over the telephone. Administering the MINI over the telephone is acceptable and was applied in other studies $[45,46]$. In this study, all modules of the MINI were used. Participants diagnosed with depression or suicide ideations or attempt were referred for appropriate care.

This study was approved by the Ethics Committee of the Riga Stradins University, Riga, Latvia. The project was conducted in accordance with the Declaration of Helsinki and its subsequent amendments. All patients were enrolled after providing written informed consent. Neither participating family practices nor patients were compensated for their participation.

\section{Statistical analysis}

The internal reliability of the PHQ-9 was assessed by Cronbach's alpha coefficient. The criterion validity of the PHQ-9 and the PHQ-2 was assessed by receiver operating characteristic (ROC) analysis. The criterion validity of the PHQ-9 and the PHQ-2 was analysed in terms of sensitivity, specificity, and positive and negative predictive values for different cut-off scores. The Latvian and Russian versions of the MINI, which is used to diagnose major depressive disorder, were used as the criterion standard. Data analyses were performed in Stata version 14 (Stata Corp). A separate analysis was conducted for the Latvian and Russian languages.

\section{Results}

In total, 1604 patients were invited to complete the PHQ-9 scale, and 1585 of them completed the PHQ9. From those who completed the PHQ-9, 100 patients did not answer a telephone call three times and were excluded, and 1485 patients were interviewed with the MINI over the telephone. In the final analysis, 1467 patients (448 men and 1019 women) were included. The questionnaires of 18 patients had to be dropped out due to insufficient data quality.

The main characteristics of those who were included in the analysis are shown in Table 1. For both languages, a separate analysis was applied. According to the MINI, $10.2 \%$ (95\% CI $8.7-11.8$ ) of the whole population had
Table 1 Characteristics of the total sample $(n=1467)$

\begin{tabular}{|c|c|c|}
\hline & $\begin{array}{l}\text { Latvian } \\
\%(n)\end{array}$ & $\begin{array}{l}\text { Russian } \\
\%(n)\end{array}$ \\
\hline Total & $100(912)$ & $100(555)$ \\
\hline Lifetime depression & $27.6(252)$ & $28.7(159)$ \\
\hline Past only depression & $19.0(173)$ & $16.4(91)$ \\
\hline Current depression & $8.7(79)$ & $12.3(68)$ \\
\hline \multicolumn{3}{|l|}{ Gender } \\
\hline Male & $30.7(280)$ & $30.3(168)$ \\
\hline Female & $69.3(632)$ & $69.7(387)$ \\
\hline \multicolumn{3}{|l|}{ Age groups } \\
\hline 18-34 & $17.7(161)$ & $8.7(48)$ \\
\hline $35-54$ & $30.6(279)$ & $31.7(176)$ \\
\hline $55-64$ & $22.3(203)$ & $26.3(146)$ \\
\hline $65+$ & $29.5(269)$ & $33.3(185)$ \\
\hline \multicolumn{3}{|l|}{ Education } \\
\hline Primary or less & $16.2(148)$ & $15.4(78)$ \\
\hline Secondary & $53.4(487)$ & $54.3(310)$ \\
\hline Higher than secondary & $29.8(272)$ & $29.7(164)$ \\
\hline No answer & $0.6(5)$ & $0.6(3)$ \\
\hline \multicolumn{3}{|l|}{ Socioeconomic status } \\
\hline Above average & $5.2(47)$ & $4.3(24)$ \\
\hline Average & $71.3(650)$ & $60.9(338)$ \\
\hline Below average & $23.5(214)$ & $34.8(193)$ \\
\hline No answer & $0.1(1)$ & $0.0(0)$ \\
\hline
\end{tabular}

current depression and $28.1 \%$ (95\% CI 25.9-30.4) had experienced at least one depressive episode in the past. Current depression was found in $8.7 \%$ of those who completed the PHQ-9 in Latvian and $12.3 \%$ in Russian. The reliability (Cronbach's alpha) for the Latvian version of the PHQ-9 scale was 0.82 and 0.79 for the Russian version.

The performance of the PHQ-9 was compared against the diagnosis of major depression as determined by the MINI, a reliable standard. The sensitivity, specificity, and likelihood ratio are presented separately for the Latvian and Russian languages in Tables 2 and 3, respectively. At a cut-off score of 8 or above, the sensitivity of the Latvian version of the PHQ-9 was 0.75 , and the specificity was 0.84 . For the Russian version of the PHQ-9, they were 0.79 and 0.80 , respectively. The positive likelihood ratio was 4.57 for the Latvian version and 4.0 for the Russian version at this cut-off score. A cut-off score of 10 for the PHQ-9 Latvian language decreased sensitivity to $60.8 \%$ and increased specificity to $91.1 \%$. A cut-off score of 10 for the PHQ-9 Russian language decreased sensitivity to $67.7 \%$ and increased specificity to $89.7 \%$. The cut-offs chosen in the ROC curve analysis where the ones closer is to the upper left corner. ROC curve analysis (Figs. 1, 2) supported the criterion validity of the PHQ-9 in 
Table 2 Sensitivity, specificity, and likelihood ratios at various cut-off points of the Latvian version of the PHQ-9

\begin{tabular}{llllrl}
\hline PHQ-9 score & $\begin{array}{l}\text { Sensitivity } \\
\text { (\%) }\end{array}$ & $\begin{array}{l}\text { Specificity } \\
\text { (\%) }\end{array}$ & $\begin{array}{l}\text { Classified } \\
\text { (\%) }\end{array}$ & LR+ & LR- \\
\hline$\geq 6$ & 82.3 & 69.6 & 70.7 & 2.71 & 0.25 \\
$\geq 7$ & 77.2 & 77.3 & 77.3 & 3.40 & 0.29 \\
$\geq 8$ & 74.7 & 83.7 & 82.9 & 4.57 & 0.30 \\
$\geq 9$ & 70.9 & 87.9 & 86.4 & 5.84 & 0.33 \\
$\geq 10$ & 60.8 & 91.1 & 88.5 & 6.84 & 0.43 \\
$\geq 11$ & 55.7 & 94.1 & 90.8 & 9.47 & 0.47 \\
$\geq 12$ & 49.4 & 95.8 & 91.8 & 11.75 & 0.53 \\
$\geq 13$ & 44.3 & 97.4 & 92.8 & 16.78 & 0.57 \\
$\geq 14$ & 36.7 & 98.2 & 92.9 & 20.39 & 0.64 \\
\hline
\end{tabular}

Table 3 Sensitivity, specificity, and likelihood ratios at various cut-off points of the Russian version of the PHQ-9

\begin{tabular}{llllrl}
\hline PHQ-9 score & $\begin{array}{l}\text { Sensitivity } \\
\text { (\%) }\end{array}$ & $\begin{array}{l}\text { Specificity } \\
(\%)\end{array}$ & $\begin{array}{l}\text { Classified } \\
(\%)\end{array}$ & LR+ & LR- \\
\hline$\geq 6$ & 92.7 & 64.2 & 67.8 & 2.59 & 0.11 \\
$\geq 7$ & 86.8 & 73.5 & 75.1 & 3.28 & 0.18 \\
$\geq 8$ & 79.4 & 80.1 & 80.0 & 4.00 & 0.26 \\
$\geq 9$ & 67.7 & 85.4 & 83.2 & 4.64 & 0.38 \\
$\geq 10$ & 67.7 & 89.7 & 87.0 & 6.59 & 0.36 \\
$\geq 11$ & 58.8 & 92.0 & 87.9 & 7.34 & 0.45 \\
$\geq 12$ & 52.9 & 93.8 & 88.8 & 8.59 & 0.50 \\
$\geq 13$ & 45.6 & 95.9 & 89.7 & 11.10 & 0.57 \\
$\geq 14$ & 35.2 & 96.3 & 88.8 & 9.55 & 0.67 \\
\hline
\end{tabular}

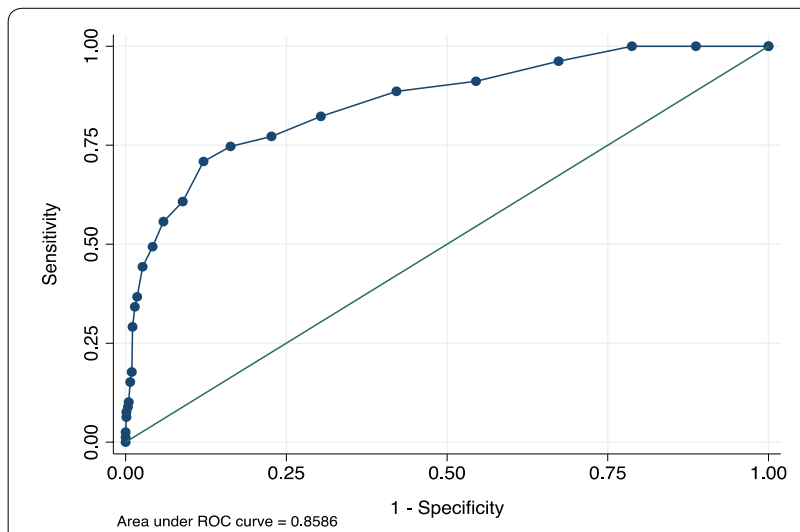

Fig. 1 The receiver operating characteristic (ROC) curve of the Latvian version of the PHQ-9 versus the MINI for the major depression diagnosis

differentiating between patients with and without major depression ( $\mathrm{AUC}=0.86$ for Latvian version and 0.88 for Russian version).

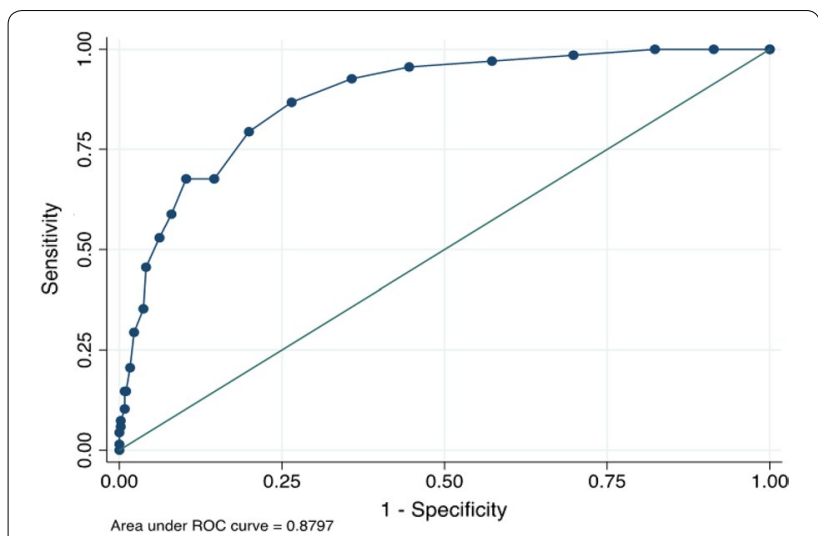

Fig. 2 The receiver operating characteristic (ROC) curve of the Russian version of the PHQ-9 versus the MINI for the major depression diagnosis

Table 4 Sensitivity, specificity, and likelihood ratios at various cut-off points of the Latvian version of the PHQ-2

\begin{tabular}{llllrl}
\hline PHQ-2 score & $\begin{array}{l}\text { Sensitivity } \\
\text { (\%) }\end{array}$ & $\begin{array}{l}\text { Specificity } \\
(\%)\end{array}$ & $\begin{array}{l}\text { Classified } \\
(\%)\end{array}$ & LR+ & LR- \\
\hline$\geq 1$ & 89.9 & 40.7 & 45.0 & 1.52 & 0.25 \\
$\geq 2$ & 78.5 & 64.6 & 65.8 & 2.22 & 0.33 \\
$\geq 3$ & 55.7 & 89.9 & 87.0 & 5.52 & 0.49 \\
$\geq 4$ & 36.00 & 94.2 & 89.4 & 6.59 & 0.66 \\
$\geq 5$ & 22.8 & 98.0 & 91.5 & 11.16 & 0.79 \\
$\geq 6$ & 15.2 & 98.4 & 91.2 & 9.73 & 0.86 \\
\hline
\end{tabular}

Table 5 Sensitivity, specificity, and likelihood ratios at various cut-off points of the Russian version of the PHQ-2

\begin{tabular}{llllrl}
\hline PHQ-2 score & $\begin{array}{l}\text { Sensitivity } \\
(\%)\end{array}$ & $\begin{array}{l}\text { Specificity } \\
(\%)\end{array}$ & $\begin{array}{l}\text { Classified } \\
(\%)\end{array}$ & LR+ & LR- \\
\hline$\geq 1$ & 94.1 & 38.2 & 45.1 & 1.52 & 0.15 \\
$\geq 2$ & 79.4 & 66.5 & 68.1 & 2.37 & 0.31 \\
$\geq 3$ & 58.8 & 87.7 & 84.1 & 4.77 & 0.47 \\
$\geq 4$ & 45.6 & 92.8 & 87.0 & 6.34 & 0.59 \\
$\geq 5$ & 27.9 & 96.3 & 87.9 & 7.56 & 0.75 \\
$\geq 6$ & 19.1 & 98.2 & 88.5 & 10.34 & 0.82 \\
\hline
\end{tabular}

We also performed validity analysis for both languages of the PHQ-2 against the MINI The sensitivity, specificity, LR + and LR - for all possible PHQ-2 thresholds for both Latvian and Russian languages are presented in Tables 4 and 5. At the threshold $\geq 2$, the PHQ-2 Latvian version correctly identified $78.5 \%$ of MINI cases (sensitivity) and $64.6 \%$ of non-cases of depression (specificity). 
The PHQ-2 Russian version correctly identified 79.4\% of cases and $66.5 \%$ of non-cases. The positive likelihood ratio was 2.21 and 2.37 at this cut-off score for the Latvian and Russian languages, respectively. The PHQ-2 demonstrated moderate overall accuracy relative to the MINI for discriminating between cases and non-cases of depression, with an AUC of 0.79 for the Latvian version and AUC of 0.80 for the Russian version.

\section{Discussion}

The main aim of this study was to assess the validity of the PHQ-9 and the PHQ-2 and to establish a cut-off score to identify depression in the nationwide sample of patients attributable to Latvia visiting their GP because of health concerns. The screener was primarily developed for use in primary care settings and is the only questionnaire that has been tested in a primary care sample in Latvia.

Instruments that can be used in both screening and scaling modes have a particular advantage in that their weaknesses can be compensated by each other [47].

Within 18 studies performed with the PHQ-9, the prevalence of depression, as diagnosed by the gold-standard tests, ranged from 2.5 to $37.5 \%$ [48]. In our study, the point prevalence of depression was estimated at $10.2 \%$, which is consistent with the findings from the other studies.

Despite the fact that the brief PHQ-9 is commonly used to screen for depression with 10 often recommended as a cut-off score, we found that a cut-off score of $\geq 8$ on the PHQ-9 was the best at detecting depression in primary care patients in Latvia. Interestingly, the optimal cutoff points for major depression fall in the severity range of 5-9, as described by Kroenke et al. [21] for the category of patients with mild depressive symptoms. In the meta-analysis by Manea et al. [48], the PHQ-9 was found to have acceptable diagnostic properties for detecting depression for cut-off scores between 8 and 11. Its validity was supported by the AUC value that suggests a moderate accuracy of the questionnaire.

The pooled estimates of sensitivity and specificity for a cut-off score of 8 reported by Manea et al. [48] were 0.82 (95\% CI 0.66-0.92) and 0.83 (95\% CI 0.69-0.92), respectively. In our study, the rates of sensitivity and specificity for the Latvian language version were 0.75 and 0.83 and for the Russian language version were 0.79 and 0.80 , respectively. In a study with primary care elderly patients, in which the criterion validity was evaluated by administering both the PHQ-9 and the MINI, the reported optimal cut-off score for major depressive disorder with the best validity characteristics was $\geq 7$ (sensitivity 0.92 , specificity 0.78) [49]. Our study showed lower sensitivity, but higher specificity. Although, we have also studied primary care populations, the comparison of the studies cannot be made easily. In our study, we included all patients who visit their GP because of medical concerns, but in the study by Lamers et al. [49], only the patients 60 years or older diagnosed with certain chronic medical disorders were included.

The sensitivity of screening instruments is considered good when their range is $0.79-0.97$ and when their specificity is $0.63-0.86$ [50]. Both languages of the PHQ-9 had relatively low sensitivity and acceptable specificity. The moderate specificity of the PHQ-9 for diagnosing major depression can be explained because it is possible to diagnose the disorder without having either of the two cardinal symptoms of major depression. As such, the summed score does not match perfectly with the MINI, which is a structured diagnostic interview based on DSM-IV criteria [51].

The internal consistency (alpha coefficient) of the PHQ-9 in this study was 0.82 for the Latvian version and 0.79 for the Russian version. For a self-report instrument to be reliable, it is suggested that Cronbach's alpha be at least 0.70 [52]. However, it was lower than that from studies in the US (alpha coefficient $=0.79-0.89)[53,54]$.

Recently, the PHQ-9 validation study in six primary care settings in Latvia was performed with a total sample size of 293 patients [42]. The estimated cut-off score was $\geq 10$ with sensitivity $86.49 \%$ and specificity $89.36 \%$ for both languages. In the pilot project of the PHQ-9 validation, the PHQ-9 validity parameters were better than in this study. It is notable that the pilot study had considerable limitations. First, there was a small number of subjects. Second, not all Latvian regions were covered; therefore, the results cannot be representative. Third, the study was conducted by one interviewer. This study was conducted with a larger sample of patients and covered all Latvian regions and was performed by four mental health professionals who specialize in psychiatry and who were blind to the PHQ-9 and PHQ-2 results.

Our findings support the fact that an estimated cut-off score of 10 cannot be generalized across countries and populations.

The 2-question screener was sensitive for diagnosis of major depression when compared with the MINI with sensitivities of 0.90 and 0.94 for Latvian and Russian versions for thresholds of 1 or greater. Sensitivities for threshold 2 or greater comprised 0.79 for both language versions of the PHQ-2, and these sensitivities were acceptable. However, the specificities for threshold 1 or greater were not acceptable, but for threshold 2 or greater they were modest for both language versions of the PHQ-2: 0.65 for the Latvian version and 0.67 for the Russian version. At the most commonly used threshold $\geq 3$ [35], the sensitivity for the Latvian and Russian 
versions was 0.56 and 0.59 and the specificity was 0.90 and 0.88 , respectively. The finding that the score $\geq 2$ was more successful at detecting depression is in accordance with similar finding reported by previous studies [55]. Another study to include a primary care sample (but not exclusively) reported a sensitivity of 0.83 and a specificity of 0.92 when the PHQ-2 (threshold score of 3 or higher) was compared with a health professional interview in 580 patients [35]. The patients who received the reference standard interview had to be contacted within $48 \mathrm{~h}$ of the screening interview. In our study, the reference standard was provided by the telephone within 2 weeks after the screening phase, which may have introduced bias into the results. A study conducted in older patients using the DSM-IV as a reference standard reported a sensitivity of 1.0 and a specificity of 0.77 for the PHQ-2 [56]. However, in this study, construct validity cut-off points were not reported. A study conducted in an outpatient clinic in Germany reported sensitivity and specificity was 78 and $79 \%$, respectively, for major depression determined by a PHQ-2 score of 3 or more [37]. At a threshold score of 3 or higher and using a recognized reference standard, our sensitivity results for the PHQ-2 are generally not as high as those of other studies. This outcome can be explained as the result of a truly consecutive sample of patients in primary care, a reference standard that was administered not immediately but within 2 weeks after screening or even simply chance. Another of the limitations is its cross-sectional design; longitudinal studies are needed to establish the sensitivity to change. Inclusion of currently diagnosed and treated patients may increase bias in studies by inflating estimates of screening accuracy [57].

The strengths of this study are that all the patients were from primary care and they all received the MINI reference standard assessment. Our study included a large sample size, covered all Latvian regions and was conducted in urban and rural settlements and is representative to primary care in Latvia. Respondents were interviewed by four psychiatrists who were blind to the PHQ-9 estimates.

\section{Conclusion and implications for practice}

In summary, the Latvian and Russian versions of the PHQ-9 and PHQ-2 have moderate psychometric properties for screening for major depression in general practice with a recommended cut-off score of 8 or greater for the PHQ-9 and 2 or greater for the PHQ-2. For GPs who wish to screen their patients for depression, we suggest they ask patients to respond to the first 2 questions of the PHQ-9 (i.e., the PHQ-2); if their score is positive (if they score 2 or more), the patients should then complete the PHQ-9.
In a study on the 12-month prevalence of depression and healthcare utilization in the general population of Latvia, certain risk factors for depression were identified [13], and these factors could be useful for GPs to identify the target population and initiate screening with the PHQ-2 and PHQ-9.

In this study, established cut-off points of the PHQ-9 and PHQ-2 together with the established risk factors for having depression in the study conducted in the general population [13] have been used within the framework of the National Research Programme, BIOMEDICINE, to develop diagnostic and treatment algorithms for depression in primary care in Latvia.

\section{Abbreviations \\ AUC: the area under curve; GP: general practitioner; LR+, LR-: likelihood ratio for positive and negative results; MINI: The Mini International Neuropsychiatric Interview; PHQ-9: The Patient Health Questionnaire-9; PHQ-2: The Patient Health Questionnaire-2; ROC: a receiver operating characteristic; US: The United States; WHO: The World Health Organization.}

\section{Authors' contributions}

ER conceived the presented idea and study design. ER, MT, JV worked on the technical details. ER, MT, RI. JV analysed the data. MT performed statistical analysis. JV wrote the manuscript in consultation with ER. All authors discussed the results and contributed to the final manuscript. All authors read and approved the final manuscript.

\section{Author details}

${ }^{1}$ Department of Psychiatry and Narcology, Riga Stradins University, Tvaika Street 2, Riga 1005, Latvia. ${ }^{2}$ Institute of Philosophy and Sociology, University of Latvia, Kalpaka bulv. 4, Riga, Latvia.

\section{Acknowledgements}

None.

\section{Competing interests}

The authors declare that they have no competing interests.

Availability of data and materials section of manuscript

Please contact author for data requests.

Consent for publication

Not applicable.

\section{Ethics approval and consent to participate}

All participants to the study gave granted informed consent. This study was approved by the Ethics Committee of the Riga Stradins University, Riga, Latvia.

\section{Funding}

The study was supported by The National Research Programme BIOMEDICINE 2014-2017 (Nr. 5.8.1.).

\section{Publisher's Note}

Springer Nature remains neutral with regard to jurisdictional claims in published maps and institutional affiliations.

Received: 16 July 2018 Accepted: 27 July 2018

Published online: 02 August 2018 


\section{References}

1. Whiteford HA, Degenhardt L, Rehm J, Baxter AJ, Ferrari AJ, Erskine HE, et al. Global burden of disease attributable to mental and substance use disorders: findings from the Global Burden of Disease Study 2010. Lancet. 2013:382(9904):1575-86.

2. Scott KM, Von Korff M, Angermeyer MC, Benjet C, Bruffaerts R, de Girolamo G, et al. Association of childhood adversities and early-onset mental disorders with adult-onset chronic physical conditions. Arch Gen Psychiatry. 2011;68(8):838-44

3. Holmstrand C, Bogren M, Mattisson C, Brådvik L. Long-term suicide risk in no, one or more mental disorders: the Lundby Study 1947-1997. Acta Psychiatr Scand. 2015;132(6):459-69.

4. Guthrie EA, Dickens C, Blakemore A, Watson J, Chew-Graham C, Lovell $K$, et al. Depression predicts future emergency hospital admissions in primary care patients with chronic physical illness. J Psychosom Res. 2016;82:54-61.

5. Parcesepe AM, Cabassa LJ. Public stigma of mental illness in the United States: a systematic literature review. Adm Policy Ment Health. 2013;40(5):384-99.

6. Ustun TB, Korff VM. Mental illness in general health care: an international study. In: Ustun TB, Sartorius N, editors. Mental illness in general health care: an international study. Chichester: Wiley; 1995. p. 347-60.

7. Hirschfeld RM, Keller MB, Panico S, Arons BS, Barlow D, Davidoff F, et al. The National Depressive and Manic-Depressive Association consensus statement on the undertreatment of depression. JAMA. 1997;277(4):333-40

8. Mitchell AJ, Vaze A, Rao S. Clinical diagnosis of depression in primary care: a meta-analysis. Lancet. 2009;374(9690):609-19.

9. Katon W, Schulberg H. Epidemiology of depression in primary care. Gen Hosp Psychiatry. 1992;14(4):237-47.

10. King M, Nazareth I, Levy G, Walker C, Morris R, Weich S, et al. Prevalence of common mental disorders in general practice attendees across Europe. Br J Psychiatry. 2008;192(5):362-7.

11. Winkler P, Krupchanka D, Roberts T, Kondratova L, Machů V, Höschl C, et al. A blind spot on the global mental health map: a scoping review of 25 years' development of mental health care for people with severe mental illnesses in central and eastern Europe. Lancet Psychiatry. 2017:4(8):634-42

12. Pulmanis T, Pelne, A, Taube, M. Mental Health in Latvia in 2013: a thematic report 2014. https://spkc.gov.lv/upload/Petijumi\%20un\%20zinojumi/ Sabiedribas\%20veselibas\%20petijumi/psihiska_veseliba_Iv_2013.pdf. Accessed June 2018.

13. Vrublevska J, Trapencieris M, Snikere S, Grinberga D, Velika B, Pudule I, et al. The 12-month prevalence of depression and health care utilization in the general population of Latvia. J Affect Disord. 2017;210:204-10.

14. Screening for Depression in Adults. US preventive services task force recommendation statement. Ann Intern Med. 2009:151(11):784-W.256. https://static1.squarespace.com/static/54d4ea02e4b0b004cf66dba6/ t/564b6e58e4b0defb2f78d64f/1447784024456/us_preventative_servi ces_task_force_recommendation.pdf. Accessed June 2018

15. Pignone MP, Gaynes BN, Rushton JL, Burchell CM, Orleans CT, Mulrow $C D$, et al. Screening for depression in adults: a summary of the evidence for the US preventive services task force. Ann Intern Med. 2002;136(10):765-76.

16. Joffres M, Jaramillo A, Dickinson J, Lewin G, Pottie K, Shaw E, et al. Recommendations on screening for depression in adults. CMAJ. 2013;185(9):775-82

17. Mokkink LB, Terwee CB, Patrick DL, Alonso J, Stratford PW, Knol DL, et al. The COSMIN study reached international consensus on taxonomy, terminology, and definitions of measurement properties for health-related patient-reported outcomes. J Clin Epidemiol. 2010;63(7):737-45.

18. El-Den S, Chen TF, Gan Y-L, Wong E, O'Reilly CL. The psychometric properties of depression screening tools in primary healthcare settings: a systematic review. J Affect Disord. 2018:225:503-22.

19. Gilbody S, Richards D, Brealey S, Hewitt C. Screening for depression in medical settings with the Patient Health Questionnaire (PHQ): a diagnostic meta-analysis. J Gen Intern Med. 2007;22(11):1596-602.

20. Spitzer RL, Kroenke K, Williams JB. Validation and utility of a self-report version of PRIME-MD: the PHQ primary care study. Primary Care Evaluation of Mental Disorders. Patient Health Questionnaire. JAMA 1999:282(18):1737-44.
21. Kroenke K, Spitzer RL, Williams JB. The PHQ-9: validity of a brief depression severity measure. Gen Intern Med. 2001;16(9):606-13.

22. Kroenke K, Spitzer RL, Williams JBW, Löwe B. The Patient Health questionnaire somatic, anxiety, and depressive symptom scales: a systematic review. Gen Hosp Psychiatry. 2010;32(4):345-59.

23. McGuire AW, Eastwood J-A, Macabasco-O'Connell A, Hays RD, Doering LV. Depression screening: utility of the patient health questionnaire in patients with acute coronary syndrome. Am J Crit Care. 2013;22(1):12-9.

24. Navinés R, Castellví P, Moreno-España J, Gimenez D, Udina M, Cañizares $S$, et al. Depressive and anxiety disorders in chronic hepatitis $C$ patients: reliability and validity of the Patient Health Questionnaire. J Affect Disord. 2012;138(3):343-51

25. Hyphantis T, Kotsis K, Voulgari PV, Tsifetaki N, Creed F, Drosos AA. Diagnostic accuracy, internal consistency, and convergent validity of the Greek version of the patient health questionnaire 9 in diagnosing depression in rheumatologic disorders. Arthritis Care Res. 2011;63(9):1313-21.

26. Gelaye B, Tadesse MG, Williams MA, Fann JR, Vander Stoep A, Andrew Zhou X-H. Assessing validity of a depression screening instrument in the absence of a gold standard. Ann Epidemiol. 2014;24(7):527-31.

27. Kiely KM, Butterworth P. Validation of four measures of mental health against depression and generalized anxiety in a community based sample. Psychiatry Res. 2015;225(3):291-8.

28. Kocalevent R-D, Hinz A, Brähler E. Standardization of the depression screener Patient Health Questionnaire (PHQ-9) in the general population. Gen Hosp Psychiatry. 2013;35(5):551-5.

29. Alonso J, Angermeyer MC, Bernert S, Bruffaerts R, Brugha TS, Bryson H, et al. Prevalence of mental disorders in Europe: results from the European Study of the Epidemiology of Mental Disorders (ESEMeD) project. Acta Psychiatr Scand Suppl. 2004;420:21-7.

30. Inoue T, Tanaka T, Nakagawa S, Nakato Y, Kameyama R, Boku S, et al. Utility and limitations of PHQ-9 in a clinic specializing in psychiatric care. BMC Psychiatry. 2012;12:73.

31. Pilkonis PA, Lan Y, Dodds NE, Johnston KL, Maihoefer CC, Lawrence SM. Validation of the depression item bank from the Patient-Reported Outcomes Measurement Information System (PROMIS ${ }^{\circledR}$ ) in a 3-month observational study. J Psychiatr Res. 2014;56:112-9.

32. Ryan TA, Bailey A, Fearon P, King J. Factorial invariance of the Patient Health Questionnaire and Generalized Anxiety Disorder Questionnaire. Br J Clin Psychol. 2013;52(4):438-49.

33. Titov N, Dear BF, McMillan D, Anderson T, Zou J, Sunderland M. Psychometric comparison of the $\mathrm{PHQ}-9$ and $\mathrm{BDI}-\mathrm{Il}$ for measuring response during treatment of depression. Cogn Behav Ther. 2011:40(2):126-36.

34. Beard C, Hsu KJ, Rifkin LS, Busch AB, Björgvinsson T. Validation of the PHQ-9 in a psychiatric sample. J Affect Disord Suppl. 2016;193(C):267-73.

35. Kroenke K, Spitzer RL, Williams JBW. The Patient Health Questionnaire-2: validity of a two-item depression screener. Med Care. 2003:41(11):1284-92.

36. Arroll B, Goodyear-Smith F, Kerse N, Fishman T, Gunn J. Effect of the addition of a "help" question to two screening questions on specificity for diagnosis of depression in general practice: diagnostic validity study. BMJ. 2005:331(7521):884-6.

37. Löwe B, Kroenke K, Gräfe K. Detecting and monitoring depression with a two-item questionnaire (PHQ-2). J Psychosom Res. 2005:58(2):163-71.

38. Arroll B, Khin N, Kerse N. Screening for depression in primary care with two verbally asked questions: cross sectional study. BMJ. 2003;327(7424):1144-6

39. Cazard F, Ferreri F. Bipolar disorders and comorbid anxiety: prognostic impact and therapeutic challenges. Encephale. 2013;39(1):66-74.

40. Central Statistical Bureau of Latvia. http://www.csb.gov.lv/sites/default/ files/skoleniem/iedzivotaji/etniskais_sastavs.pdf. Accessed June 2018.

41. Rancans E, Vrublevska J, Snikere S, Koroleva I, Trapencieris M. The point prevalence of depression and associated sociodemographic correlates in the general population of Latvia. J Affect Disord. 2014;156:104-10.

42. Vrublevska J, Trapencieris M, Rancans E. Adaptation and validation of the Patient Health Questionnaire-9 to evaluate major depression in a primary care sample in Latvia. Nord J Psychiatry. 2017:72:1-7.

43. Sheehan DV, Lecrubier $Y$, Sheehan KH, Amorim P, Janavs J, Weiller E, et al. The Mini-International Neuropsychiatric Interview (MINI): the development and validation of a structured diagnostic psychiatric interview for DSM-IV and ICD-10. J Clin Psychiatry. 1998:59(Suppl 20):22-33. 
44. Pinninti NR, Madison $\mathrm{H}$, Musser $\mathrm{E}$, Rissmiller D. MINI international neuropsychiatric schedule: clinical utility and patient acceptance. Eur Psychiatry. 2003;18(7):361-4.

45. Duburcq A, Blin P, Charpak Y, Blachier C, Allicar MP, Bouhassira M, et al. Use of a structured diagnostic interview to identify depressive episodes in an epidemiologic study: a posteriori internal validation. Rev Epidemiol Sante Publique. 1999;47(5):455-63.

46. Heckman CJ, Cohen-Filipic J, Darlow S, Kloss JD, Manne SL, Munshi T. Psychiatric and addictive symptoms of young adult female indoor tanners. Am J Health Promot. 2014;28(3):168-74.

47. Nease DE Jr, Maloin JM. Depression screening: a practical strategy. J Fam Pract. 2003;52(2):118-24.

48. Manea L, Gilbody S, McMillan D. Optimal cut-off score for diagnosing depression with the Patient Health Questionnaire (PHQ-9): a meta-analysis. CMAJ. 2012;184(3):E191-6.

49. Lamers F, Jonkers CCM, Bosma H, Penninx BWJH, Knottnerus JA, van Eijk JTM. Summed score of the Patient Health Questionnaire-9 was a reliable and valid method for depression screening in chronically ill elderly patients. J Clin Epidemiol. 2008;61(7):679-87.

50. Robins LN, Wing J, Wittchen HU, Helzer JE, Babor TF, Burke J, et al. The composite international diagnostic interview. An epidemiologic Instrument suitable for use in conjunction with different diagnostic systems and in different cultures. Arch Gen Psychiatry. 1988;45(12):1069-77.
51. Stafford L, Berk M, Jackson HJ. Validity of the Hospital Anxiety and Depression Scale and Patient Health Questionnaire-9 to screen for depression in patients with coronary artery disease. Gen Hosp Psychiatry. 2007;29(5):417-24.

52. Streiner DL, Norman GR. Scaling responses. 2nd ed., Health Measurement Scales: a practical guide to their development and useOxford: Oxford University Press; 1995.

53. Huang FY, Chung H, Kroenke K, Delucchi KL, Spitzer RL. Using the Patient Health Questionnaire-9 to measure depression among racially and ethnically diverse primary care patients. J Gen Intern Med. 2006;21(6):547-52.

54. Lee PW, Schulberg HC, Raue PJ, Kroenke K. Concordance between the PHQ-9 and the HSCL-20 in depressed primary care patients. J Affect Disord. 2007;99(1-3):139-45.

55. Arroll B, Goodyear-Smith F, Crengle S, Gunn J, Kerse N, Fishman T, et al. Validation of PHQ-2 and PHQ-9 to screen for major depression in the primary care population. Ann Fam Med. 2010;8(4):348-53.

56. Li C, Friedman B, Conwell Y, Fiscella K. Validity of the Patient Health Questionnaire 2 (PHQ-2) in identifying major depression in older people. J Am Geriartr. 2007;55(4):596-602.

57. Rice DB, Thombs BD. Risk of bias from inclusion of currently diagnosed or treated patients in studies of depression screening tool accuracy: a cross-sectional analysis of recently published primary studies and metaanalyses. PLOS ONE. 2016;11(2):e0150067.
Ready to submit your research? Choose BMC and benefit from:

- fast, convenient online submission

- thorough peer review by experienced researchers in your field

- rapid publication on acceptance

- support for research data, including large and complex data types

- gold Open Access which fosters wider collaboration and increased citations

- maximum visibility for your research: over $100 \mathrm{M}$ website views per year

At BMC, research is always in progress.

Learn more biomedcentral.com/submissions 